\title{
EXPERIÊNCIAS DE APOIO, DIÁLOGO E INTERAÇÃO COM MOVIMENTOS SOCIAIS NA AGÊNCIA DE JORNALISMO DA UEPG ${ }^{1}$
}

\author{
Experiences of support, dialogue and interaction with social movements at \\ Agencia de Jornalismo from UEPG
}

\author{
Karina Janz Woitowicz ${ }^{2}$ \\ Isadora Ortiz de Camargo ${ }^{3}$ \\ Sérgio Luiz Gadini ${ }^{4}$
}

\begin{abstract}
RESUMO
O presente trabalho destaca a importância da extensão universitária no diálogo e apoio a manifestações populares e movimentos sociais locais, através do Projeto Agência de Jornalismo, mantido pelo curso de Jornalismo da Universidade Estadual de Ponta Grossa (UEPG). As atividades realizadas através do referido projeto têm fomentado a integração entre estudantes, professores envolvidos e sociedade civil.

Palavras-chave: extensão acadêmica; demandas sociais de informação; produção jornalística.
\end{abstract}

\begin{abstract}
The present work highlights the importance of university extension in dialogues and support to the protests and local social movements through the Project Agencia de Jornalismo, run by the Journalism course from the State University of Ponta Grossa (UEPG). The activities undertaken through this project have encouraged the integration of students, professors and the civil society concerned.
\end{abstract}

Keywords: academic extension; social demands for information; news production.

\section{RESUMEN}

El trabajo destaca la importancia de la extensión universitaria en el dialogo y apoyo a las manifestaciones populares y movimientos sociales locales, a través del Proyecto Agência de Jornalismo, mantenido por el curso de Periodismo de la Universidad Estadual de Ponta Grossa (UEPG). Las actividades realizadas a través del referido proyecto han fomentado la integración entre estudiantes, profesores involucrados y sociedad civil.

Palabras-clave: extensión académica; demandas sociales de información; producción periodística.

\footnotetext{
1 Uma versão preliminar do presente texto foi apresentada no VIII Encontro Paranaense de Pesquisa em Jornalismo, realizado em outubro de 2010, na UEPG.

2 Professora Dra. do curso de Jornalismo da Universidade Estadual de Ponta Grossa/PR. E-mail: $<$ karinajw@hotmail.com>.

${ }^{3}$ Formanda em Jornalismo pela Universidade Estadual de Ponta Grossa/PR. Foi estagiária do projeto Agência de Jornalismo em 2010. E-mail: <isa_camargo16@hotmail.com>.

4 Dr. em Comunicação, professor do curso de Jornalismo da Universidade Estadual de Ponta Grossa/PR, presidente do Fórum Nacional de Professores de Jornalismo (FNPJ) e coordenador do projeto Agência de Jornalismo. E-mail: <sergiogadini@yahoo.com.br>.
}

WOITOWICZ, Karina J; CAMARGO, Isadora O.; GADINI, Sérgio L. Experiências de apoio, diálogo e interação com movimentos sociais na Agência de Jornalismo da UEPG. Extensão em Foco, Curitiba: Ed. da UFPR, nr.9, jan/jun 2014, p.117-129. ISSN 2358-7180. 
"A prática da extensão é uma das ações que marca e legitima a inserção da universidade pública brasileira no cotidiano de uma parcela da população historicamente excluída das condições de acesso à cidadania" (Luiz Naue)

\section{Introdução}

O projeto de extensão Agência de Jornalismo, desenvolvido no Departamento de Comunicação da Universidade Estadual de Ponta Grossa (UEPG), visa integrar setores da comunidade universitária e da sociedade civil organizada com o Curso de Jornalismo, a partir de atividades de produção em mídia, com ênfase no apoio a organizações sem fins lucrativos e movimentos sociais, que não dispõem de estrutura para divulgar suas ações.

Criada no segundo semestre de 2003, a Agência de Jornalismo atende algumas (dentre um número cada vez maior) demandas de informação e produção jornalística da comunidade interna e externa à Universidade. Ao longo de sua atuação, a Agência já desenvolveu uma série de parcerias com a sociedade civil e com os cursos e setores da UEPG, atendendo a solicitações para a cobertura de eventos, produção jornalística (vídeos, jornais, sites, folders, cartazes, dentre outros produtos), auxílio na organização de eventos e suporte para produções científicas.

Nos últimos três anos, tais demandas se intensificaram, exigindo uma atuação mais sistemática do projeto no atendimento às mais variadas ações, realizando trabalhos de caráter jornalístico de forma voluntária e sem qualquer finalidade lucrativa. No presente trabalho, serão destacadas as atividades realizadas pela Agência em parceria com diversos setores da sociedade. Em seu aspecto estrutural, o projeto conta com o apoio da Pró-Reitoria de Extensão (PROEX) da UEPG, através da concessão de um bolsista no convênio com a Fundação Araucária do Estado do Paraná.

O projeto Agência de Jornalismo visa oportunizar a prática jornalística através da extensão. Com ações de inserção comunitária e produção acadêmica, busca-se contribuir para a formação profissional dos(as) estudantes em uma perspectiva voltada à qualidade da produção jornalística e ao comprometimento com a defesa da cidadania. 


\section{O lugar da produção laboratorial na formação em Jornalismo}

Oportuno lembrar que o processo de formação profissional em Jornalismo, ao longo destes últimos anos (1990), registra esforços de fortalecimento de ações extensionistas em cursos de Jornalismo, seja em instituições públicas ou privadas, basicamente em torno de duas preocupações que apontam para um mesmo eixo de atuação.

Por um lado, está o desafio de apostar em projetos que integram os estudantes ao meio profissional com ênfase em demandas sociais de mídia, buscando ampliar laços de envolvimento com setores da sociedade civil organizada que poderiam contribuir para a formação profissional em Jornalismo, na medida em que tais ações universitárias não precisariam ficar reféns ou mesmo dependentes das relações de mercado (norteadas, habitualmente, pela lógica da eficácia do lucro e da rentabilidade econômica).

Em outro aspecto, a mesma estratégia de aposta visa complementar a formação universitária em Jornalismo, buscando inserir os futuros profissionais em ações sociais que envolvem processos de produção editorial. Deste modo, resolve o dilema de estágio profissional que, sempre que não fica regulamentado, acaba por provocar a redução de postos de trabalhos em sintonia com uma espécie de "exploração" antecipada de mão-de-obra profissional, poucas vezes reconhecida por seu valor comercial, sob a alegação de que tais estudantes estariam "aprendendo" pelo aval de empresas de mídia.

É no mesmo sentido, embora não exclusivamente, que a proposta de Diretrizes Nacionais Curriculares em Jornalismo - atualmente em tramitação no Conselho Nacional de Educação $(\mathrm{CNE})^{5}$ - situa o problema do estágio profissionalizante na área. Isso porque empresas regionais onde se situam as escolas de Jornalismo podem não dar conta de ações em parceria, deixando sob responsabilidade das próprias Instituições a tarefa de encontrar espaço (ou criar), a partir da identificação de demandas sociais, a serem exploradas nas diferentes regiões de abrangência e ação das respectivas escolas.

A proposta de Diretrizes em Jornalismo, portanto, vem ao encontro de iniciativas - como é o caso da Agência de Jornalismo da UEPG - que apostam

\footnotetext{
${ }^{5}$ Outras informações sobre o projeto das Diretrizes Curriculares aos Cursos de Jornalismo podem ser verificadas no site da Fenaj: <http://www.fenaj.org.br/materia.php?id=3184>.
}

WOITOWICZ, Karina J; CAMARGO, Isadora O.; GADINI, Sérgio L. Experiências de apoio, diálogo e interação com movimentos sociais na Agência de Jornalismo da UEPG. Extensão em Foco, Curitiba: Ed. da UFPR, nr.9, jan/jun 2014, p.117-129. ISSN 2358-7180. 
em ações de parceria com setores da sociedade civil, possibilitando assim que os próprios estudantes envolvidos possam se aproximar mais concretamente das diferentes situações de comunicação e particularmente de eventuais demandas por produtos, serviços ou espaços de produção jornalística.

Aliás, vale aqui lembrar que, há alguns anos, a própria Federação Nacional de Jornalistas (FENAJ) mantém, entre suas estratégias de ação junto aos cursos de Jornalismo, um Programa de Qualidade da Formação em Jornalismo e o Programa Nacional de Estágio Acadêmico em Jornalismo ${ }^{6}$. As duas referidas propostas têm apoio do Fórum Nacional de Professores de Jornalismo (FNPJ). Propostas estas que em muito se aproximam do atual projeto em pauta das Diretrizes Curriculares no Ensino de Jornalismo ${ }^{7}$ e, neste caso, também dialoga com a estratégia extensionista que caracteriza o Projeto Agência de Jornalismo da UEPG.

\section{Produção jornalística através da extensão}

As atividades da Agência de Jornalismo envolvem alunos e professores do curso, propiciando a troca de informações e o aperfeiçoamento da formação profissional em diferentes áreas. A Agência prevê a prestação de serviços nas áreas de assessoria de comunicação e produção jornalística em diversos formatos (áudio, vídeo, on-line ou impresso).

As solicitações enviadas à Agência são analisadas e distribuídas nas equipes de trabalho, sendo realizadas de forma gratuita, preservando o caráter público da instituição. O projeto envolve acadêmicos (as) de todas as séries do curso e contempla professores que atuam em diferentes áreas, oportunizando o contato com práticas e experiências do jornalismo.

Com esta iniciativa, o curso de Jornalismo busca experimentar atividades práticas em comunicação, tendo como parâmetro as demandas de informação de diferentes setores da comunidade, em especial, e no caso em

6 As propostas da Federação Nacional dos Jornalistas sobre o assunto podem ser conferidas no link: <http://www.fenaj.org.br/educ.php>.

7 Considerada uma reivindicação histórica de professores e dirigentes sindicais do Jornalismo em nível nacional, a proposta de Diretrizes Curriculares ao Ensino de Jornalismo visa fortalecer as especificidades da profissão, conforme projeto que no final de 2010 tramita junto ao Conselho Nacional de Educação (CNE).

WOITOWICZ, Karina J; CAMARGO, Isadora O.; GADINI, Sérgio L. Experiências de apoio, diálogo e interação com movimentos sociais na Agência de Jornalismo da UEPG. Extensão em Foco, Curitiba: Ed. da UFPR, nr.9, jan/jun 2014, p.117-129. ISSN 2358-7180. 
questão, as ações do curso de Jornalismo em parceria com setores da sociedade civil.

As ações do Projeto são realizadas de acordo com as demandas sociais (e, em alguns casos, de setores da Universidade) mediadas por estudantes e professores, que participam da Agência de Jornalismo. Paralelamente à interação com a sociedade civil, o projeto possibilita exercícios laboratoriais acadêmicos, na medida em que as atividades demandam produções jornalísticas (ou de mídia).

$O$ atendimento à comunidade interna da UEPG também se configura como um importante espaço de atuação do projeto. Considerando apenas os últimos três anos (2007-2009), foram realizadas principalmente atividades de organização de eventos, incluindo elaboração da arte, produção de sites e anais, cobertura de eventos, com destaque para a Semana de Estudos em Comunicação da UEPG, Seminário de Inverno de Jornalismo UEPG, $X$ Conferência Brasileira de Folkcomunicação, Encontro Paranaense de Pesquisa em Jornalismo, II Encontro Paranaense de Rádios Comunitárias, Ciclo de Estudos em Linguagem (Letras UEPG), dentre outros eventos e iniciativas.

Outras parcerias internas (no âmbito da Universidade) importantes dizem respeito à Incubadora de Empreendimentos Solidários (IESOL), ao vídeo para a Biblioteca Central, ao documentário do Fenata (PROEX), à diagramação do Jornal da UATI (Universidade Aberta da Terceira Idade), além de várias edições da Revista Internacional de Folkcomunicação, publicação científica com periodicidade semestral produzida pela Agência em parceria com a Cátedra Unesco de Comunicação no Brasil e a Rede Brasileira de Pesquisadores em Folkcomunicação8.

A principal dinâmica (metodológica) utilizada na Agência de Jornalismo decorre da identificação de demandas, ou procura, por parte de setores da sociedade civil organizada, que solicitam apoio para alguma atividade, iniciativa ou ação, na maioria das vezes para divulgar e dar visibilidade a seus respectivos trabalhos. A partir de pedidos encaminhados por representantes de entidades e movimentos sociais, as atividades são avaliadas pelo grupo gestor

\footnotetext{
${ }^{8}$ A Rede de Estudos e Pesquisas Folkcom pode ser acessada pelo site <http://www.redefolkcom.org/>.

WOITOWICZ, Karina J; CAMARGO, Isadora O.; GADINI, Sérgio L. Experiências de apoio, diálogo e interação com movimentos sociais na Agência de Jornalismo da UEPG. Extensão em Foco, Curitiba: Ed. da UFPR, nr.9, jan/jun 2014, p.117-129. ISSN 2358-7180.
} 
da Agência e, em seguida, estudantes de Jornalismo desenvolvem tais ações, sob a orientação de professores do curso.

Para os estudantes, assessorar organizações não governamentais (mesmo que muitas vezes de forma esporádica) possibilita uma maior interação com as necessidades sociais de mídia, tendo por base a importância de planejar e executar serviços ou produtos jornalísticos. Nesse sentido, há um aprendizado e resultado de propostas importantes no âmbito regional que vão além do ensino dentro da sala de aula.

Por se caracterizar como extensão universitária, que é a interlocução entre academia e comunidade, a extensão faz com que o estudante se integre com o espaço em que vive, desenvolvendo atividades sociais, culturais, que colaboram com a população deste local. Nesse sentido, "trata-se de um relacionamento entre teoria e prática", em que o conhecimento se estende para fora da sala de aula e é reproduzido no meio social, o que permite a aprendizagem por meio da aplicação. (SILVA, 1996, apud ARAÚJO; CASIMIRO, , p. ).

A extensão universitária revela-se como uma obrigatoriedade constitucional disposta no artigo 207, da Constituição Brasileira. Declara que "as universidades gozam de autonomia didático-científica, administrativa e da gestão financeira e patrimonial e obedecerão ao princípio da indissociabilidade entre ensino, pesquisa e extensão". (ARAÚJO; CASIMIRO,, p. ).

No caso da Agência de Jornalismo, as atividades são, em geral, produções midiáticas realizadas por alunos do curso (estagiários e bolsistas) para os movimentos sociais da cidade sem fins lucrativos, que não tem recursos para bancar uma assessoria midiática. Mas além dessa assessoria promovida pela agência, há o papel orgânico do Projeto, em que participantes e voluntários se organizam para desenvolver eventos para tais entidades, além do que já é produzido como padrão - texto, release, audiovisual e fotografia.

\section{Contribuições sociais nas atividades de extensão}

O projeto, em certos aspectos, opera como espaço de intervenção técnica de produção editorial, na medida em que realiza atividades jornalísticas 
em mídia impressa, eletrônica ou digital, tais como a produção de jornais, cartazes, folders, vinhetas ou documentários radiofônicos, sites, dentre outros formatos em suportes variados, a partir de solicitações de setores comunitários.

$\mathrm{Na}$ mesma dinâmica de valorização das iniciativas envolvendo a sociedade civil de Ponta Grossa, desde fevereiro/2010, o Projeto Agência de Jornalismo da UEPG já apoiou ações como o Movimento de Combate à Corrupção Eleitoral (MCCE/Comitê PG), auxiliou na organização do Io Fórum de Representação e Legitimidade Política dos Campos Gerais, Ato Público em Defesa da Transparência Política e contra os "diários secretos" na Assembleia Legislativa do PR (realizado em 31/03/10), manifestação de um ano sem diploma no Jornalismo Brasileiro (17/06/10), além do apoio ao Plebiscito pelo Limite da Propriedade da Terra (Fórum Reforma Agrária, realizado entre os dias 01 e 07/09/10), dentre outras ações, sempre focadas no interesse público e coletivo de Ponta Grossa, Região e Brasil.

Quadro 1. Produções da Agência de Jornalismo em 2008

\begin{tabular}{|l|l|l|l|l|l|}
\hline Suporte & Vídeo & Áudio & Blog/site & $\begin{array}{l}\text { Texto/ } \\
\text { cartaz }\end{array}$ & Evento \\
\hline Jornal Monteiro Lobato & & & X & X & \\
\hline Assessoria Grupo Fauna & $\mathrm{X}$ & & $\mathrm{X}$ & $\mathrm{X}$ & $\mathrm{X}$ \\
\hline $\begin{array}{l}\text { Assessoria Encontro } \\
\text { Regional de Atualidades } \\
\text { Florestais e da Madeira }\end{array}$ & & & $\mathrm{X}$ & $\mathrm{X}$ & \\
\hline Jornal IPC Genro & & & & $\mathrm{X}$ & \\
\hline $\begin{array}{l}\text { Prêmio Adelmo } \\
\text { Filho }\end{array}$ & & & & $\mathrm{X}$ & $\mathrm{X}$ \\
\hline $\begin{array}{l}\text { II Encontro Paranaense } \\
\text { de Rádio }\end{array}$ & $\mathrm{X}$ & & $\mathrm{X}$ & $\mathrm{X}$ \\
\hline Revista Folkcomunicação & & & $\mathrm{X}$ & $\mathrm{X}$ & \\
\hline
\end{tabular}

Em 2008, nas produções da Agência de Jornalismo figuraram desde os suportes impressos até os eletrônicos, com a sua existência e manutenção em 
rede até hoje ${ }^{9}$. Algumas das ações desenvolvidas em parceria com entidades locais foram o Jornal do Monteiro, com edição bimestral para o Conjunto Residencial Monteiro Lobato, de Ponta Grossa - duas edições concluídas; assessoria do Grupo Fauna - produção de blog/site e material de divulgação da ONG; assessoria ao Encontro Regional de Atualidades Florestais e da Madeira, com produção de informativo; produção do Jornal IPC (Instituto Cidadania, de Ponta grossa) - duas edições concluídas. Houve também a elaboração de material de divulgação, como no caso do folder do III Prêmio Adelmo Genro Filho de Pesquisa em Jornalismo (SBPJor 2008); cartaz, folder e organização do I/ Encontro Paranaense de Rádios Comunitárias, evento que resultou na criação da Federação Paranaense de Emissoras Comunitárias (FEMARCOM-PR), na UEPG, em agosto de 2008. Outra iniciativa do Projeto é a formatação do novo site da Revista Internacional de Folkcomunicação, periódico mantido pela Rede de Pesquisadores em Folkcomunicação e Cátedra Unesco de Comunicação no Brasil (www.revistas.uepg.br), além da produção da Revista Internacional de Folkcomunicação (www.revistas.uepg.br), edições de julho/2008 e dezembro/2008.

Em 2009, a Agência de Jornalismo, em parceria com entidades e movimentos sociais, produziu o material de divulgação do evento alusivo ao dia da Abolição da Escravatura, organizado pela Sociedade Afro-Brasileira Cacique Pena Branca (SACPB) de Ponta Grossa; e a realização da assessoria de mídia para a ONG Você Consegue, em campanha de doação de medula óssea. A Agência de Jornalismo também foi responsável pela organização da coleta de sangue na UEPG, em parceria com o Hemepar e o Centro Acadêmico de Jornalismo UEPG; pelo apoio à coleta de assinaturas para o projeto Ficha Limpa em parceria com o Comitê PG do Movimento de Combate à Corrupção Eleitoral (MCCE); pelo apoio na organização e divulgação do Dia Mundial sem Carro (em 23 de setembro de 2009); pela organização da $I^{\underline{a}}$

\footnotetext{
${ }^{9}$ A escolha do período a partir de 2008 tem a justificativa do tempo viável para um breve texto descritivo de uma experiência extensionista, mas também coincide com a criação da estrutura operacional (como câmera de vídeo, ilha de edição e outros suportes técnicos) viabilizada a partir da execução do projeto de "Reestruturação Laboratorial do Curso de Jornalismo da UEPG", financiado pela Secretaria de Estado de Ciência e Tecnologia através da Unidade do Fundo Gestor do Governo PR, sob a coordenação técnica de Sérgio Gadini. Foi o referido projeto que impulsionou a realização de inúmeras atividades atualmente em andamento na UEPG a partir dos laboratórios de ensino, em parceria com grupos de pesquisa e extensão no Curso de Jornalismo.
}

WOITOWICZ, Karina J; CAMARGO, Isadora O.; GADINI, Sérgio L. Experiências de apoio, diálogo e interação com movimentos sociais na Agência de Jornalismo da UEPG. Extensão em Foco, Curitiba: Ed. da UFPR, nr.9, jan/jun 2014, p.117-129. ISSN 2358-7180. 
Conferência Livre de Comunicação; pela captação de imagens para a produção de um documentário sobre o movimento do transporte público, além da produção do material de divulgação dos quatro eventos do calendário anual do Departamento de Comunicação (Semana de Integração da Resistência, Seminário de Inverno, Semana de Comunicação e Encontro Paranaense de Pesquisa em Jornalismo).

\section{Quadro 2. Produções da Agência de Jornalismo em 2009}

\begin{tabular}{|l|l|l|l|l|l|}
\hline Suporte & Vídeo & Áudio & $\begin{array}{l}\text { Blog/Si } \\
\text { te }\end{array}$ & Texto/Cartaz & Evento \\
\hline $\begin{array}{l}\text { Sociedade Afro- } \\
\text { Brasileira Cacique Pena } \\
\text { Branca }\end{array}$ & & & & $\mathrm{X}$ & $\mathrm{X}$ \\
\hline ONG Você Consegue & $\mathrm{X}$ & $\mathrm{X}$ & & $\mathrm{X}$ & $\mathrm{X}$ \\
\hline MCCE Mov Ficha Limpa & & & & $\mathrm{X}$ & $\mathrm{X}$ \\
\hline $\begin{array}{l}\text { Coleta de Sangue } \\
\text { Hemepar }\end{array}$ & & & & $\mathrm{X}$ & $\mathrm{X}$ \\
\hline $\begin{array}{l}\text { Dia Mundial sem Carro } \\
\text { (23 set em PG) }\end{array}$ & & $\mathrm{X}$ & & $\mathrm{X}$ & $\mathrm{X}$ \\
\hline $\begin{array}{l}\text { Ia Conferência Livre de } \\
\text { Comunicação PG }\end{array}$ & $\mathrm{X}$ & & & $\mathrm{X}$ & $\mathrm{X}$ \\
\hline $\begin{array}{l}\text { Revista Folkcom (Rede e } \\
\text { Cátedra Unesco Com } \\
\text { BR) }\end{array}$ & & $\mathrm{X}$ & & \\
\hline $\begin{array}{l}\text { Movimento } \\
\text { Transporte Público em } \\
\text { PG }\end{array}$ & $\mathrm{X}$ & & & $\mathrm{X}$ & $\mathrm{X}$ \\
\hline
\end{tabular}

Como mostram os quadros, as atividades realizadas na Agência de Jornalismo podem ser classificadas como apoio aos movimentos sociais e à sociedade civil de Ponta Grossa, ao mesmo tempo em que se classificam como iniciativas experimentais, em que estudantes têm a possibilidade de exercitar a prática desenvolvida no curso de Jornalismo, como a produção de textos, a edição audiovisual, e também a relação com experiências de organização de eventos e mobilização social. Nesse sentido, a Agência, como um projeto de 
extensão universitária, cultiva um intercâmbio profissional e cultural entre os participantes do projeto, professores e comunidade.

Quadro 3. Produções da Agência de Jornalismo em 2010

\begin{tabular}{|l|l|l|l|l|l|}
\hline Suporte & Vídeo & Áudio & Blog/site & $\begin{array}{l}\text { Texto/ } \\
\text { cartaz }\end{array}$ & Evento \\
\hline MCCE PG & & & $\mathrm{X}$ & $\mathrm{X}$ & \\
\hline $\begin{array}{l}\text { M. Campos Gerais... de } \\
\text { Igual para Igual? }\end{array}$ & $\mathrm{X}$ & $\mathrm{X}$ & & $\mathrm{X}$ & $\mathrm{X}$ \\
\hline $\begin{array}{l}\text { Plebiscito pelo Limite da } \\
\text { Propriedade de Terra }\end{array}$ & & $\mathrm{X}$ & & & \\
\hline $\begin{array}{l}\text { Manifestação Em Defesa } \\
\text { do Diploma de Jornalismo }\end{array}$ & $\mathrm{X}$ & $\mathrm{X}$ & & $\mathrm{X}$ & $\mathrm{X}$ \\
\hline $\begin{array}{l}\text { Ato em Defesa da } \\
\text { Transparência Política } \\
\text { (3103) }\end{array}$ & & & $\mathrm{X}$ & $\mathrm{X}$ \\
\hline $\begin{array}{l}\text { Sociedade Afro-Brasileira } \\
\text { Cacique Pena Branda }\end{array}$ & & & $\mathrm{X}$ & $\mathrm{X}$ \\
\hline $\begin{array}{l}\text { Revista Folkcom (Rede } \\
\text { Cátedra da Unesco de } \\
\text { Comunicação) }\end{array}$ & & & $\mathrm{X}$ & & \\
\hline $\begin{array}{l}\text { TV Comunitária de Ponta } \\
\text { Grossa }\end{array}$ & $\mathrm{X}$ & $\mathrm{X}$ & $\mathrm{X}$ & & \\
\hline $\begin{array}{l}\text { Parque Histórico } \\
\text { Carambeí }\end{array}$ & $\mathrm{X}$ & & & & \\
\hline
\end{tabular}

Questões de relevância social também são salientadas através de parcerias com outros setores que são encaminhadas à Agência de Jornalismo. Iniciativas realizadas entre o final de 2009 e o começo de 2010, como a produção e o fomento ao blog do Movimento de Combate à Corrupção Eleitoral (MCCE) de Ponta Grossa, contendo informações, divulgação da cartilha Ficha Limpa, entre outros serviços disponibilizados aos usuários, confirmam a relevância social do projeto.

Destaca-se, também, a realização do / Fórum de Representação e Legitimidade Política dos Campos Gerais, que possibilitou o encontro dos candidatos a deputado estadual e federal, governo e senado pelo Estado do Paraná, nos dias 4 e 6 de agosto de 2010, de maneira que aproximou a comunidade de alguns candidatos pela Região (PG), proporcionando um debate de relevância social, que gerou vídeo, texto, cartazes e fotos através da parceria com o Movimento Campos Gerais... de Igual para Igual.

WOITOWICZ, Karina J; CAMARGO, Isadora O.; GADINI, Sérgio L. Experiências de apoio, diálogo e interação com movimentos sociais na Agência de Jornalismo da UEPG. Extensão em Foco, Curitiba: Ed. da UFPR, nr.9, jan/jun 2014, p.117-129. ISSN 2358-7180. 
A Agência também auxilia na organização das manifestações desses movimentos. Ao longo desses anos de existência, atos como a defesa de um Aterro Público em Ponta Grossa e mesmo eventuais auxílios ao Movimento dos Sem Terra, como o incentivo à Campanha ${ }^{10}$ de doação de livros pela criação da Biblioteca Comunitária Emiliano Zapata (em Ponta Grossa), mostram-se ações que indicam relevantes apoios da Agência de Jornalismo na cobertura, produção e divulgação midiática dos materiais desenvolvidos.

Outros exemplos mais recentes podem ser citados, como a coleta de assinaturas em apoio ao Plebiscito Popular pelo Limite da Propriedade de Terra, movimento organizado pelo Fórum Nacional de Reforma Agrária e Justiça no Campo (www.limitedaterra.org.br), realizado pelas entidades que integram o Comitê na Cidade, como o Diretório Central de Estudantes e sindicatos de trabalhadores locais; auxílio na produção e edição do vídeodocumentário do Projeto Parque Histórico de Carambeí, ao centenário da imigração holandesa no Paraná; além do apoio no Ato Público em Defesa à Transparência Política no Estado do Paraná, realizado em 31/03/2010, em parceria com entidades parceiras pró-cidadania, Voto Consciente e Centro Acadêmico João do Rio.

A partir do final de março de 2010, a Agência de Jornalismo passa a assumir novas atividades na divulgação dos eventos do calendário anual do Curso de Jornalismo, pois o lançamento do projeto "Diálogos de Mídia Regional" implica na edição de um calendário para cada painel, que acontece na última semana de cada mês, além da produção de textos para divulgar os "Diálogos". No final de novembro, a edição da coletânea de textos e palestras de convidados ao projeto também foi mais uma produção da Agência de Jornalismo UEPG.

E, por fim, a partir de novembro de 2010, a Agência de Jornalismo, também por demanda e solicitação, entrou no apoio ao processo de instalação da TV Comunitária de Ponta Grossa, que passou a ser operada pelo canal 96

\footnotetext{
${ }^{10}$ A referida campanha surgiu no final de 2009 e consiste na divulgação e coleta de livros pró-formação de uma Biblioteca Comunitária junto ao Assentamento Emiliano Zapata, em Ponta Grossa. A campanha conta com marca-página exclusivo e links com a respectiva arte da iniciativa. Até o momento já foram coletados (e repassados à organização do projeto) centenas de livros ou materiais para o acervo bibliográfico. A campanha tem apoio do Projeto Portal Comunitário (www.portalcomunitario.jor.br) e da IESOL.
}

WOITOWICZ, Karina J; CAMARGO, Isadora O.; GADINI, Sérgio L. Experiências de apoio, diálogo e interação com movimentos sociais na Agência de Jornalismo da UEPG. Extensão em Foco, Curitiba: Ed. da UFPR, nr.9, jan/jun 2014, p.117-129. ISSN 2358-7180. 
da Net cabo na cidade. Tal apoio se traduziu na produção de spots e vinhetas institucionais à TV Com, em especial na edição de tais produtos para inserção institucional, bem como na produção do blog da emissora comunitária local (http://tvcompg.wordpress.com). Oportuno ainda lembrar que muitas outras atividades são realizadas, em função de demandas emergenciais, que não ficam registradas nos relatórios do Projeto, mas acabam se tornando rotina na prática da extensão pela Agência.

A criação de um blog próprio da Agência (http://blogdaagencia.blogspot.com), a partir de abril de 2010, também impulsionou a divulgação de ações em andamento, pois sempre que envolvem apoio do Projeto, tais iniciativas recebem divulgação simultânea e imediata, junto ao referido espaço eletrônico, reforçando a visibilidade das referidas atividades.

\section{Considerações Finais}

A partir destas experiências, a Agência de Jornalismo também cumpre com uma das funções (desafiantes) da Universidade Pública: "integrar" setores sociais, historicamente excluídos do acesso à educação superior, através da oferta de produtos, de serviços ou de ações, em sintonia com as demandas de informação de grupos, de organizações e de entidades sociais.

As contribuições da extensão podem, assim, ser verificadas nos ganhos pedagógicos proporcionados pelo Projeto, à medida que tais ações permitem o contato com a produção laboratorial e o aprimoramento da interação da Universidade com os setores sociais.

Ao se observar o trabalho da Agência de Jornalismo no atendimento às demandas de comunicação, pode-se notar um crescente fortalecimento de iniciativas baseadas no diálogo e na parceria com a comunidade acadêmica e com os movimentos sociais, contribuindo para uma maior visibilidade dos projetos e ações. Assim, entende-se que as ações extensionistas representam um importante espaço para a projeção da produção acadêmica e o envolvimento com a comunidade e as entidades sociais, como revelam as dezenas de trabalhos viabilizados pelo Projeto Agência ao longo dos primeiros oito anos de sua existência.

WOITOWICZ, Karina J; CAMARGO, Isadora O.; GADINI, Sérgio L. Experiências de apoio, diálogo e interação com movimentos sociais na Agência de Jornalismo da UEPG. Extensão em Foco, Curitiba: Ed. da UFPR, nr.9, jan/jun 2014, p.117-129. ISSN 2358-7180. 


\section{REFERÊNCIAS}

FENAJ. Programa Nacional de Estímulo à Qualidade da Formação em Jornalismo. Disponível em: <http://www.fenaj.org.br/educacao/programa_ qualidade_ensino_2004.pdf>. Acesso em: 07/10/2010.

MELO, José Marques de; GOBBI, Maria Cristina; SATHLER, Luciano. Mídia cidadã, utopia brasileira. São Bernardo do Campo: Universidade Metodista de São Paulo, 2006.

NOGUEIRA, Maria das Dores Pimentel. Políticas de extensão universitária brasileira. Belo Horizonte: UFMG, 2005.

OLIVEIRA, Maria José da Costa (Org.). Comunicação Pública. Campinas: Alínea, 2004.

OTTAVIANI, Edelcio; TOTORA, Silvana. Educação e extensão universitária. São Paulo: Paulinas, 2010.

UNIVERSIDADE ESTADUAL DE PONTA GROSSA. Agência de Jornalismo. Projeto de Extensão Universitária. Disponível em: <http://www.uepg.br/ agenciadejornalismo/>. Acesso em: 31/08/2010.

WOITOWICZ, Karina J; CAMARGO, Isadora O.; GADINI, Sérgio L. Experiências de apoio, diálogo e interação com movimentos sociais na Agência de Jornalismo da UEPG. Extensão em Foco, Curitiba: Ed. da UFPR, nr.9, jan/jun 2014, p.117-129. ISSN 2358-7180. 